\title{
Silencing CDR las inhibits colorectal cancer progression through regulating microRNA-7
}

\author{
This article was published in the following Dove Press journal: \\ OncoTargets and Therapy \\ 7 April 2017 \\ Number of times this article has been viewed
}

Wentao Tang*
Meiling Ji*
Guodong He*
Liangliang Yang
Zhengchuan Niu
Mi Jian
Ye Wei
Li Ren
Jianmin Xu
Department of General Surgery,
Zhongshan Hospital, Fudan University,
Shanghai, People's Republic of China
*These authors contributed equally
to this work
to this work

\begin{abstract}
An increasing number of studies have demonstrated that circular RNAs (circRNAs) can regulate gene expression through interacting with microRNAs. In this study, we analyzed the expression of antisense to CDR1 as in colorectal cancer (CRC). CDR1 as had a higher expression in CRC tissues compared to adjacent, normal mucosa and was positively associated with tumor size, T stage, lymph node metastasis, and poor overall survival (OS). Downregulation of CDR1as suppressed CRC cell proliferation and invasion and increased microRNA-7 (miR-7) expression. Intriguingly, ectopic expression of miR-7 in CRC cells consistently inhibited proliferation and invasion, and the miR-7 inhibitor was able to rescue the function of CDR1as knockdown. Mechanistic studies demonstrated that CDR1as silencing suppressed EGFR and IGF-1R expression, which could be partially blocked by the miR-7 inhibitor. Finally, positive correlations between CDR1as expression and EGFR and IGF-1R expression were observed in CRC samples. Thus, given the importance of CDR1as in blocking miR-7 and positively regulating EGFR and IGF-1R, dysregulated CDR1as expression may play an important role in CRC progression.
\end{abstract}

Keywords: CDR1as, colorectal cancer, microRNA-7, proliferation

\section{Introduction}

Colorectal cancer (CRC) is one of the most common malignancies in the world and the third leading cause of cancer-related mortality in both men and women. ${ }^{1}$ It is estimated that there are 1.36 million new CRC cases and 694,000 CRC-related deaths globally each year. ${ }^{2}$ In China, CRC is the fifth most commonly diagnosed cancer and also the fifth leading cause of cancer death. ${ }^{3}$ Although the clinical achievements for the early stage of CRC are remarkable, the 5-year survival rate is only $12.5 \%$ for CRC patients with metastases. ${ }^{4}$ Approximately $20 \%$ of CRC patients have metastases at initial diagnosis, and almost $50 \%$ of CRC patients will develop metastases. ${ }^{5}$ Therefore, the investigation of the molecular mechanisms involved in CRC progression remains crucial for developing novel and effective therapies.

Circular RNA (circRNA) is a large class of RNA with covalently joined $3^{\prime}$ and 5' ends formed by back splice. Although the existence of circRNAs in mammalian cells was indicated more than 3 decades ago, ${ }^{6}$ they were mistaken as rare existing transcriptional noise. ${ }^{7}$ Through high-throughput RNA sequencing and bioinformatic analysis, thousands of different circRNAs in animal cells have been identified. ${ }^{8-13}$ Several studies have shown that circRNAs are abundantly expressed and evolutionarily conserved across the eukaryotic tree of life, thus suggesting potential biological functions. ${ }^{10,14}$

Recent studies have demonstrated that circRNAs are able to function as microRNA (miRNA) sponges, eg, circRNA-Sry acts as a sponge for miR-138 and circRNA-ITCH
Correspondence: Jianmin Xu; Li Ren Department of General Surgery, Zhongshan Hospital, Fudan University, Fenglin Road I80, Shanghai 200032, People's Republic of China Tel +86 2l 64041990 ext 2357 Email xujmin@aliyun.com; ren.li@zs-hospital.sh.cn (c) (1) (5) 2017 Tang et al. This work is published and licensed by Dove Medical Press Limited. The full terms of this license are available at https://www.dovepress.com/terms.php (c) 1 By $\mathrm{NC}$ and incorporate the Creative Commons Attribution - Non Commercial (unported, v3.0) License (http:///creativecommons.org/licenses/by-nc/3.0/). By accessing the work you hereby accept the Terms. Non-commercial uses of the work are permitted without any further permission from Dove Medical Press Limited, provided the work is properly attributed. For permission for commercial use of this work, please see paragraphs 4.2 and 5 of our Terms (https://www.dovepress.com/terms.php). 
serves as a sponge for microRNA-7 (miR-7), miR-17, and miR-214. ${ }^{9,10,15}$ Antisense to the cerebellar degenerationrelated protein 1 transcript (CDR1as) harbors $\sim 70$ conserved binding sites and acts as a strong sponge for miR-7., 910 Overexpression of CDR1as can induce developmental defects in embryonic zebrafish midbrain and regulate insulin transcription and secretion in islet cells through blocking miR-7. ${ }^{16}$ In addition, CDR 1as promotes hepatocellular carcinoma cell proliferation and invasion and serves as a risk factor for hepatic microvascular invasion. ${ }^{17,18}$ However, the expression profile, function, and underlying signaling cascade of CDR1as involved in CRC progression remain unclear.

In the present study, we sought to investigate the role of CDR1as in CRC progression and the underlying mechanisms. We found that the CDR1as/miR-7 axis critically regulates CRC progression.

\section{Materials and methods Human tissues and cell lines}

A total of 40 pairs of human primary CRC tissues and normal mucosa tissues and another 182 consecutive CRC samples were collected at the Zhongshan Hospital of Fudan University between October 2011 and April 2012. Tissue samples were immediately frozen in liquid nitrogen and stored at $-80^{\circ} \mathrm{C}$. All patients received radical primary tumor resections, and no preoperative adjuvant radiotherapy and/ or chemotherapy was administered. For patients with highrisk II stage or III/IV stage disease, postoperative adjuvant chemotherapy was given according to the CRC guidelines of the National Comprehensive Cancer Network. This study was approved by the Clinical Research Ethics Committee of Zhongshan Hospital of Fudan University, and all methods were performed in accordance with the relevant guidelines and regulations. All human samples and clinical data were obtained with written informed consent. Overall survival (OS) was calculated from the day of surgery to the date of CRC-related death or last follow-up.

The human CRC cell lines, HCT-116 and DLD-1, and human normal colonic epithelium cell lines, NCM460 and CCD841CoN, were purchased from the Chinese Academy of Sciences (Shanghai, China). HCT-116 was maintained in McCoy's 5a and DLD-1 in Roswell Park Memorial Institute (RPMI)-1640 medium. Both of them were supplemented with $10 \%$ fetal bovine serum (FBS). NCM460 and CCD841CoN were cultured in Dulbecco's Modified Eagle's Medium (DMEM) containing 20\% FBS.

\section{RNA extraction and quantitative real- time reverse transcription polymerase chain reaction (RT-PCR)}

Total RNA was extracted using RNeasy Mini Kit (QIAGEN, Hilden, Germany). cDNA was synthesized with PrimeScript ${ }^{\circledR}$ RT-PCR Kit (Takara, Kusatsu, Japan). Quantitative RT-PCR (qRT-PCR) was performed using SYBR ${ }^{\circledR}$ Premix Ex Taq ${ }^{\mathrm{TM}}$ (Takara) on an ABI 7500 platform (Applied Biosystems, Carlsbad, CA, USA). Beta actin was used as an internal control for mRNA detection. The primer sequences for mRNA detection are listed in Table S1.

For miR-7 detection, specific bulge-loop ${ }^{\mathrm{TM}}$ miR-7 primers were purchased from RiboBio (Guangzhou, China). U6 small nuclear RNA was used as an internal control for miRNA detection.

\section{Lentivirus and miRNA transfection}

The lentivirus targeting human CDRlas was purchased from GeneChem (Shanghai, China). The targeting sequence was designed as follows: 1 sense 5'-TGCACCTGTGTCAAGG TCTTTTCAAGAGAAAGACCTTGACACAGGTGCTTT TTTC- $3^{\prime}$ and 2 sense 5'-TGGTCTTCCAGCGACTTCAAT TCAAGAGATTGAAGTCGCTGGAAGACCA-3’.

miR-7 mimics and inhibitors were synthesized by RiboBio. The miRNA oligonucleotides were transfected using Lipofectamine ${ }^{\circledR}$ RNAiMAX $^{\mathrm{TM}}$ (50 nmol/L; Invitrogen, CA, USA).

\section{Cell viability assay}

After $72 \mathrm{~h}$ lentivirus infection or $24 \mathrm{~h}$ miRNA transfection, HCT-1 16 (2,500/well) and DLD-1 (3,000/well) cells were planted into 96 -well culture plates. Cell viability was measured at 24, 48, 72, 96, and $120 \mathrm{~h}$ post seeding, by using the Cell Counting Kit-8 (Dojindo, Kumamoto, Japan) according to the manufacturer's instructions.

\section{Cell cycle assay}

Seventy-two hours after infection, cells were harvested, washed with phosphate-buffered saline (PBS), and fixed in $70 \%$ ethanol at $4{ }^{\circ} \mathrm{C}$ overnight. After fixation, cells were washed with PBS before suspension in RNase $\mathrm{A} /$ propidium iodide solutions $(100 \mathrm{mg} / \mathrm{mL}$ RNase $\mathrm{A}$ and $5 \mu \mathrm{g} / \mathrm{mL}$ propidium iodide). Cells were incubated at room temperature for an hour. Stained cells were analyzed by a FACScan flow cytometer (BD Biosciences, Mountain View, CA, USA). 


\section{Annexin V/propidium iodide apoptosis assay}

Cell apoptosis was assessed by annexin V/propidium iodide (BD Biosciences, San Jose, CA, USA). Cells were harvested, washed with PBS, and resuspended in $1 \times$ binding buffer at a concentration of $1 \times 10^{6}$ cells $/ \mathrm{mL}$. A total of $100 \mu \mathrm{L}$ solution was transferred to a new tube and added with $5 \mu \mathrm{L}$ of APC Annexin V and $5 \mu \mathrm{L}$ of propidium iodide. Cells were incubated at room temperature for $15 \mathrm{~min}$ in the dark and then analyzed by a FACScan flow cytometer.

\section{Colony-formation assay}

HCT-116 (400/well) and DLD-1 (800/well) cells were seeded in six-well plates after $72 \mathrm{~h}$ lentivirus infection. The culture medium was changed every 3 days. After incubating for 2 weeks, colonies were fixed with $4 \%$ paraformaldehyde for $15 \mathrm{~min}$ and stained with 5\% Giemsa for $20 \mathrm{~min}$. The colonies containing at least 50 cells were scored.

\section{Cell invasion assay}

The cell invasion assay was performed in 24-well transwell chambers pre-coated with Matrigel (Corning, NY, USA). After $72 \mathrm{~h}$ lentivirus infection, HCT- 116 cells $\left(8 \times 10^{4}\right)$ and DLD-1 cells $\left(1.2 \times 10^{5}\right)$ in $200 \mu \mathrm{L}$ serum-free medium were seeded into the upper chamber, and the lower chamber was filled with $600 \mu \mathrm{L}$ medium containing 10\% FBS. After incubating for $24 \mathrm{~h}$, cells on the inner membrane were removed with a cotton swab. The outer membrane was fixed and stained using the HEMA 3 Manual Staining System (Thermo Fisher Scientific, Waltham, MA, USA). Cell numbers were counted and averaged in five random fields at a magnification of $100 \times$.

\section{Western blot}

Whole protein extracts were lysed by radioimmunoprecipitation assay (RIPA) buffer (Thermo Fisher Scientific) according to the manufacturer's protocol. At that time, $30 \mu \mathrm{g}$ proteins were run on a10\% sodium dodecyl sulfate polyacrylamide gel electrophoresis (SDS-PAGE) gel at $100 \mathrm{~V}$ for $2 \mathrm{~h}$ and transferred to a polyvinylidene fluoride membrane at $80 \mathrm{~V}$ for $2 \mathrm{~h}$. Membranes were blocked with $5 \%$ bovine serum albumin (BSA) in Tris buffered saline with Tween-20 (TBST) at room temperature for $1 \mathrm{~h}$. They were then incubated overnight at $4{ }^{\circ} \mathrm{C}$ with one of the following primary antibodies: anti-EGFR $(1: 2,000)$ and anti-IGF-1R $(1: 1,000)$ from Cell Signaling Technology (Danvers, MA, USA) and anti-beta actin $(1: 1,000)$ from Santa Cruz Biotechnology (Dallas, Texas, USA). After washing with TBST, membranes were incubated with secondary antibodies for $1 \mathrm{~h}$ at room temperature and signals were developed using an enhanced chemiluminescence kit (Pierce, Waltham, MA, USA).

\section{Statistical analysis}

Data were presented as mean \pm standard deviation. Significant differences between the groups were found using the student's $t$-test and the Mann-Whitney $U$ test. The correlation of CDR1as, EGFR, and IGF-1R expression was determined by the Pearson correlation test.

\section{Results \\ CDR I as is highly expressed in CRC}

CDR1as expression was measured in $40 \mathrm{CRC}$ samples and corresponding adjacent, normal tissues by qRT-PCR. Higher CDR 1as expression was detected in 29 out of 40 (72.50\%) CRC samples (Figure 1A). CDR1as also had a higher expression in CRC cell lines compared to normal colonic epithelium cell lines (Figure 1B). qRT-PCR analysis of additional 182 consecutive CRC samples revealed that high CDR 1 as expression was correlated with sex $(P=0.003)$, tumor size $(P=0.032)$, primary pT stage $3 / 4(P=0.003)$, and primary pN stage $1 / 2(P=0.002$; Table 1$)$. Kaplan-Meier analysis indicated that patients with a high CDR 1 as expression had a significantly poorer OS (hazard ratio [HR] $=1.799$, $95 \%$ confidence interval $[\mathrm{CI}]=[1.055-3.068], P=0.034)$ than patients with a low CDR1as expression (Figure 1C).

\section{CDR I as downregulation inhibits tumor cell proliferation}

Two colon cell lines HCT-116 and DLD-1 were infected with lentivirus containing either shRNA targeting CDR1as (shCDR1as) or control-scrambled shRNA (shCON). qRTPCR analysis showed that both the shRNAs effectively decreased CDR1as mRNA expression. This resulted in decreased cell viability, as measured by a CCK-8 assay (Figure 2A). Cell-cycle analysis further demonstrated that CDR1as knockdown induced a G0/G1 population increase from $58.0 \%$ to $76.3 \%$ in HCT-116 cells and from $51.1 \%$ to $69.2 \%$ in DLD-1 cells (Figure 2B). To investigate whether cell apoptosis also contributes to the decrease of cell viability, cell apoptosis was analyzed by flow cytometry. No significant apoptosis increase was observed in HCT-116 cells upon CDR1as knockdown (Figure 2C). Consistently, CDR1as silencing significantly impaired the colony-formation capacity of CRC cells (Figure 2D). Together, these data suggest that CDR1as may play an important role in CRC proliferation. 

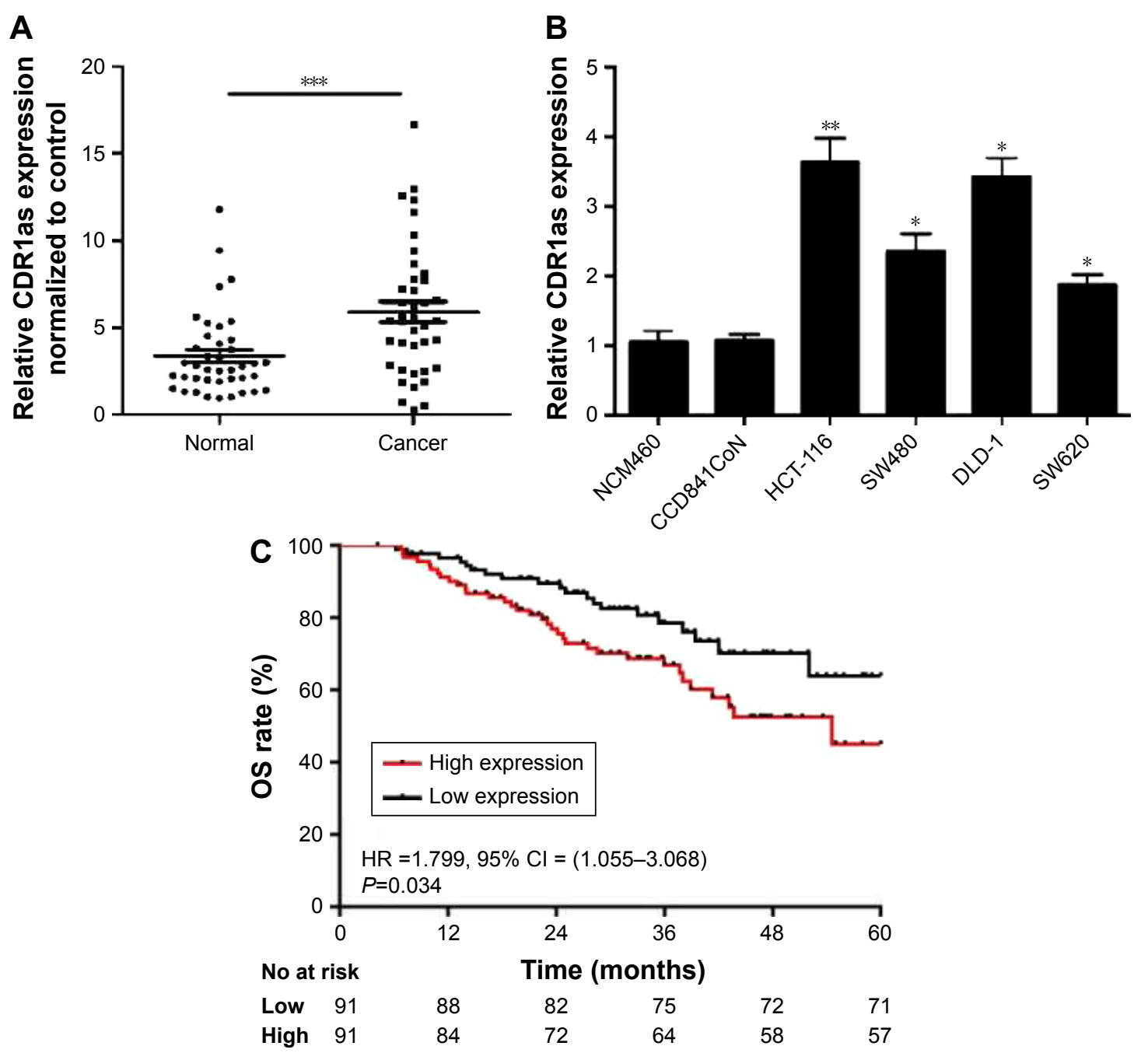

Figure I CDR I as is highly expressed in CRC.

Notes: (A) qRT-PCR analysis of CDR I as expression in 40 paired CRC tissues and adjacent normal tissues. (B) qRT-PCR analysis of CDR Ias expression in four colon cancer cell lines and two normal epithelial cell lines. (C) Kaplan-Meier curve of OS with CDRI as in CRC patients. $* P<0.05$, $* * P<0.01$, and $* * * P<0.00$ I.

Abbreviations: CRC, colorectal cancer; qRT-PCR, quantitative reverse transcription polymerase chain reaction; OS, overall survival; HR, hazard ratio; CI, confidence interval.

\section{CDR las downregulation suppresses tumor cell invasion}

Based on the significant association between CDR1as expression and tumor $\mathrm{pT}$ and $\mathrm{pN}$ stages in $\mathrm{CRC}$ samples, the effect of CDR1as on CRC cell invasion was also investigated. Knockdown of CDR1as significantly inhibited cell invasion, as determined by a transwell assay (Figure 3A). Western blot analysis further showed that MMP-9 was decreased upon CDR1 as knockdown (Figure 3B). Together, these data suggest that CDR1as also regulates cell invasion in CRC.

\section{CDR I as promotes CRC progression through partially blocking miR-7}

Previous studies have demonstrated that CDR1as could function as an miR-7 antagonist with a high binding capacity. ${ }^{9,10}$
To determine whether miR-7 expression was negatively correlated with CRC progression and CDRlas expression, qRT-PCR analysis of miR-7 from the 182 tumor samples was carried out. miR-7 expression was not significantly correlated with any clinicopathological factors (Table S2). In addition, there was no significant correlation between miR-7 and CDR1 as expression (Figure S1). However, miR-7 expression was significantly increased in both HCT-116 and DLD-1 cell lines upon CDR1as knockdown (Figure 4A). To further determine whether miR-7 and CDR1 as have opposite functions in CRC, HCT-116 and DLD-1 cells were treated with miR-7 mimics by transient transfection. Overexpression of miR-7 led to a significant decrease in cell viability in both HCT-116 and DLD-1 cells (Figure 4B). In addition, miR-7 mimics significantly resulted in a G0/G1 population increase in both the two cell lines and had no effect on cell 
Table I Correlations between CDRlas expression and clinicopathological parameters in CRC

\begin{tabular}{|c|c|c|c|}
\hline Characteristic & $\mathbf{n}$ & $\begin{array}{l}\text { CDRlas expression, } \\
\text { median (range) }\end{array}$ & $P$-value \\
\hline Sex & & & $0.003 *$ \\
\hline Female & 83 & $2.18(0.53-4.98)$ & \\
\hline Male & 99 & $3.87(1.46-8.93)$ & \\
\hline Age (years) & & & 0.584 \\
\hline$<60$ & 68 & $2.68(0.55-7.22)$ & \\
\hline$\geq 60$ & 114 & $2.83(1.00-7.80)$ & \\
\hline Location & & & 0.561 \\
\hline Right colon & 40 & $2.55(0.8 I-5.54)$ & \\
\hline Left colon & 57 & $2.85(0.75-10.43)$ & \\
\hline Rectum & 85 & $2.85(1.02-7.18)$ & \\
\hline Tumor size $(\mathrm{cm})$ & & & $0.032 *$ \\
\hline$<5$ & 111 & $2.57(0.52-7.16)$ & \\
\hline$\geq 5$ & 71 & $3.87(1.46-8.13)$ & \\
\hline Histology & & & 0.166 \\
\hline Adenocarcinoma & 149 & $2.95(1.13-7.54)$ & \\
\hline Mucinous adenocarcinoma & 33 & $\mathrm{I} .88(0.38-8.25)$ & \\
\hline Primary $\mathrm{p} T$ stage & & & $0.003 *$ \\
\hline $1 / 2$ & 37 & $1.09(0.24-4.70)$ & \\
\hline $3 / 4$ & 145 & $2.95(1.40-8.08)$ & \\
\hline Primary pN stage & & & $0.002 *$ \\
\hline 0 & 95 & $1.57(0.77-5.79)$ & \\
\hline $1 / 2$ & 87 & $2.65(1.09-7.26)$ & \\
\hline Synchronous distant metastasis & & & 0.221 \\
\hline No & 158 & $2.74(0.75-7.24)$ & \\
\hline Yes & 24 & $3.36(2.33-8.3 I)$ & \\
\hline Stage & & & 0.433 \\
\hline I, II & 88 & $2.59(0.76-7.64)$ & \\
\hline III, IV & 94 & $2.83(1.24-7.48)$ & \\
\hline Preoperative CEA level & & & 0.331 \\
\hline$<5$ & 99 & $2.95(0.77-7.8 \mathrm{I})$ & \\
\hline $5-19$ & 49 & $2.47(0.89-4.21)$ & \\
\hline$\geq 20$ & 34 & $2.96(1.38-9.87)$ & \\
\hline
\end{tabular}

Note: * represents $P<0.05$.

Abbreviations: $C R C$, colorectal cancer; $C E A$, carcinoembryonic antigen.

apoptosis (Figure 4C and D). This suggests that miR-7 mimics has an opposite function of CDR1as. To further determine whether the function of CDRlas silencing is dependent on miR-7, an miR-7 inhibitor was transiently transfected into both HCT-116 and DLD-1 cells with CDR1as knockdown. The miR-7 inhibitor significantly increased the cell viability and invasion (Figure 4E and F). Collectively, these results suggest that CDR1as may function through partially blocking miR-7.

\section{CDR I as positively regulates EGFR and IGF-IR expression in CRC}

To further determine which miR-7 targets were involved in the growth and invasion promoting effect of CDR1as in CRC, a panel of growth and invasion-related miR-7 targets was chosen for qRT-PCR analysis. Only EGFR and IGF-1R were downregulated in CDR1as knockdown HCT-116 cells (Figure 5A). Western blot analysis further confirmed that EGFR and IGF-1R were decreased in CDR1as knockdown HCT-116 cells (Figure 5B). To further test whether EGFR and IGF-1R were directly regulated by CDR1as/miR-7 axis, CDR1as knockdown HCT-116 cells were transfected with the miR-7 inhibitor. Western blot analysis demonstrated that the miR-7 inhibitor partially rescued CDR1as silencinginduced EGFR and IGF-1R downregulation (Figure 5C). Furthermore, qRT-PCR analysis of the first 40 CRC samples also demonstrated a positive correlation between CDR1as expression and $E G F R$ and $I G F-1 R$ expressions (Figure 5D). Together, these results suggest that EGFR and IGF-1R were direct targets of CDR1as/miR-7 in CRC.

\section{Discussion}

In this study, CDR1as was found to be highly expressed in 40 sample pairs, containing CRC tumor samples and normal mucosa. Further analysis in additional 182 consecutive CRC patients revealed that a higher CDR1as expression was correlated with worse OS. Knockdown of CDR1as increased miR-7 expression, suppressed CRC cell proliferation and invasion, and inhibited EGFR and IGF-1R expression.
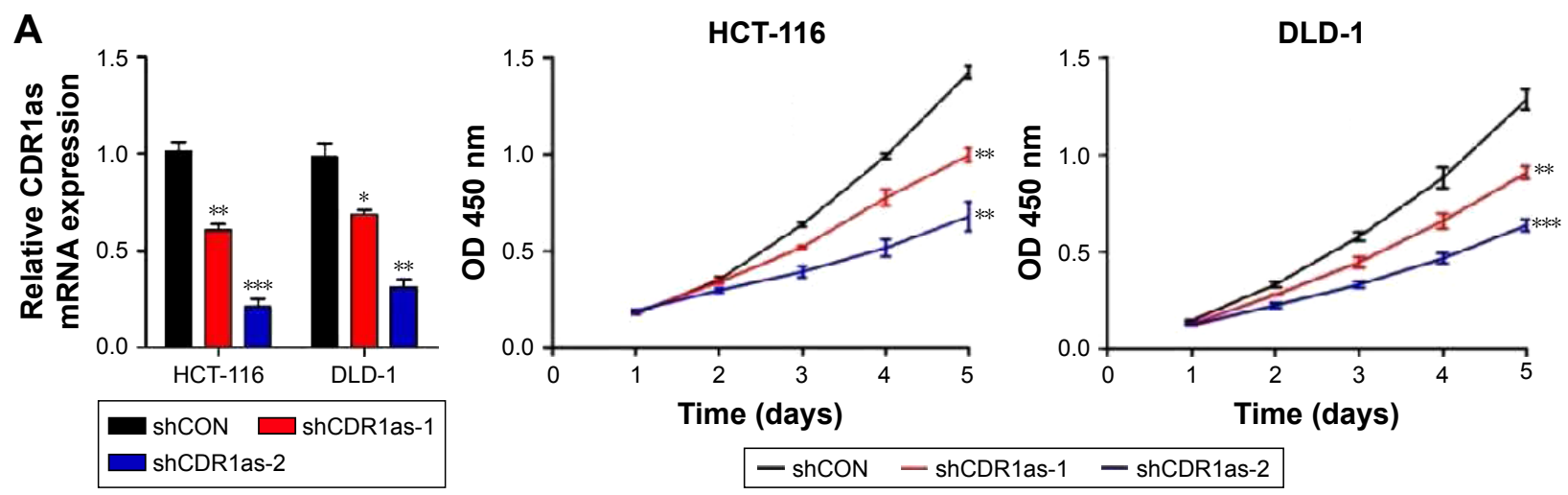

- shCON - shCDR1as-1 - shCDR1as-2

Figure 2 (Continued) 
B
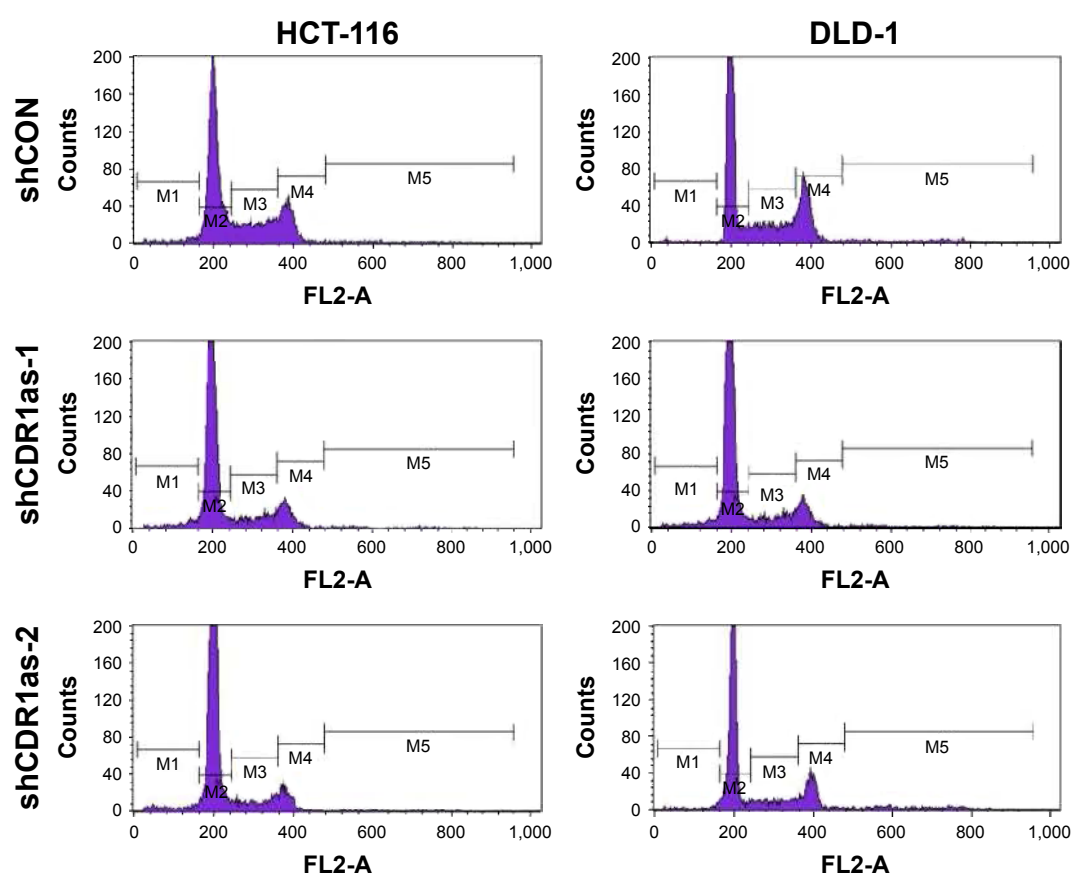

C
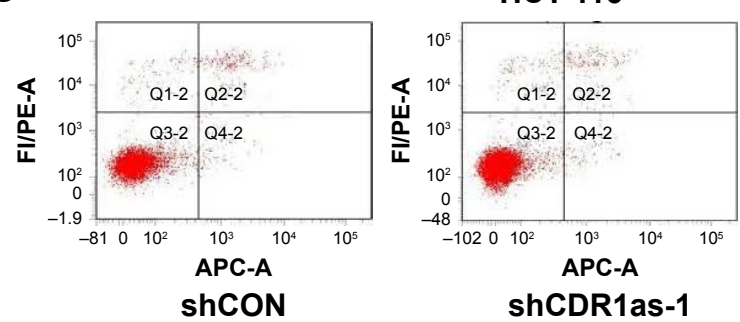

shCDR1as-1

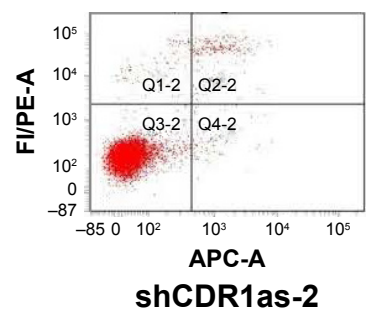

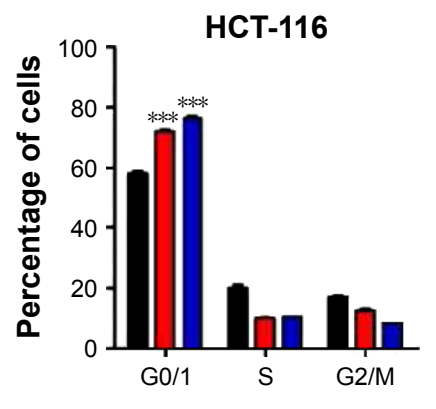

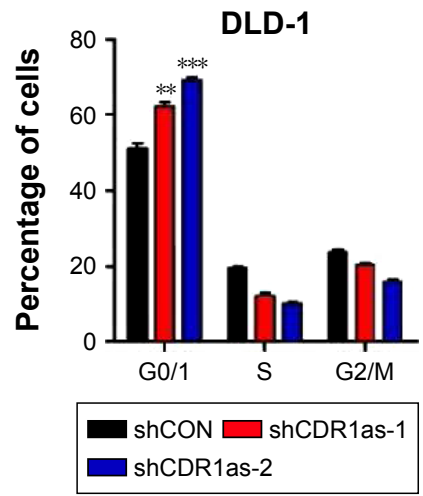

D

HCT-116

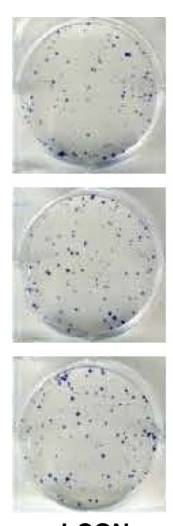

shCON

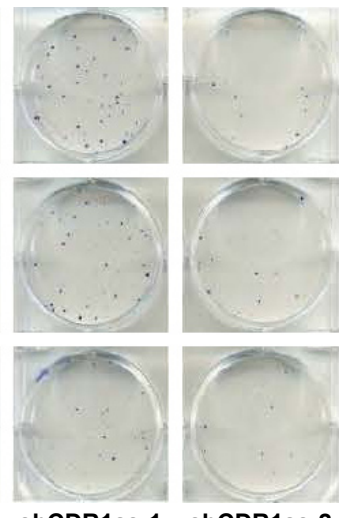

shCDR1as-1 shCDR1as-2

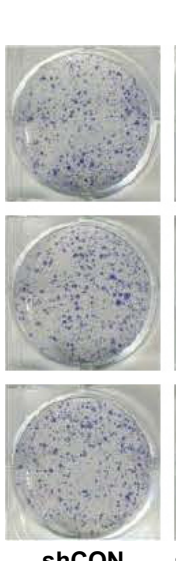

shCON

\section{DLD-1}

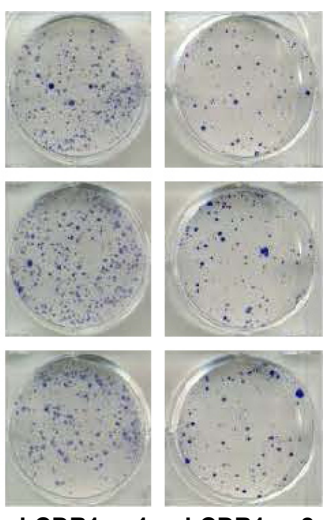

shCDR1as-1 shCDR1as-2
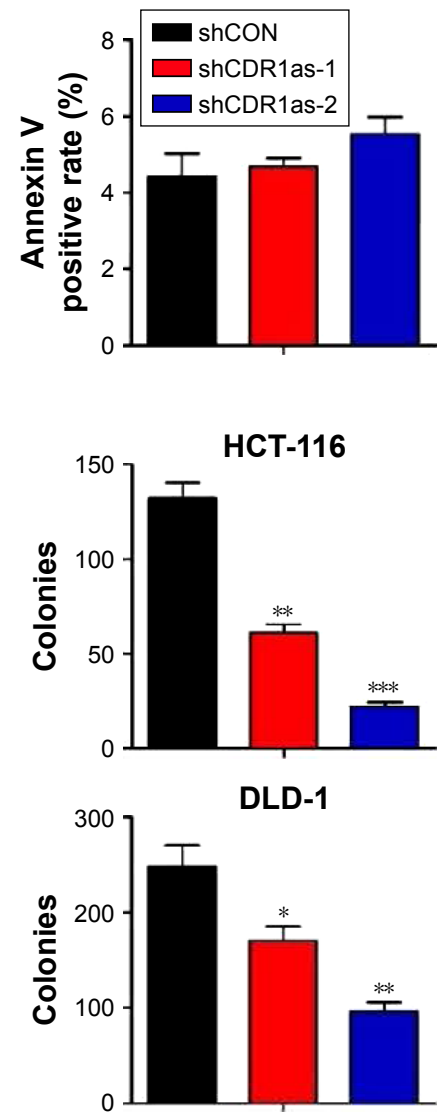

shCON $\square$ shCDR1as-1 shCDR1as-2

Figure $2 \mathrm{CDR}$ las downregulation inhibits tumor cell proliferation.

Notes: (A) qRT-PCR analysis of CDRIas expression and cell viability analysis in shCON and shCDR Ias lentivirus-infected HCT-II6 and DLD-I cells. (B) Cell-cycle distributions of HCT-II6 and DLD-I cells infected with shCON or shCDR las lentivirus for $72 \mathrm{~h}$. (C) CDR las knockdown did not significantly increase apoptosis rate in colon cancer HCT-II 6 cells. (D) Colony images and counts of shCON and shCDR Ias lentivirus-infected HCT-II6 and DLD-I cells. $* P<0.05$, $* * P<0.0$ I and $* * * P<0.00$ I. Abbreviations: qRT-PCR, quantitative reverse transcription polymerase chain reaction; shCON, control-scrambled shRNA; shCDRIas, shRNA targeting CDRIas; OD, optical density. 

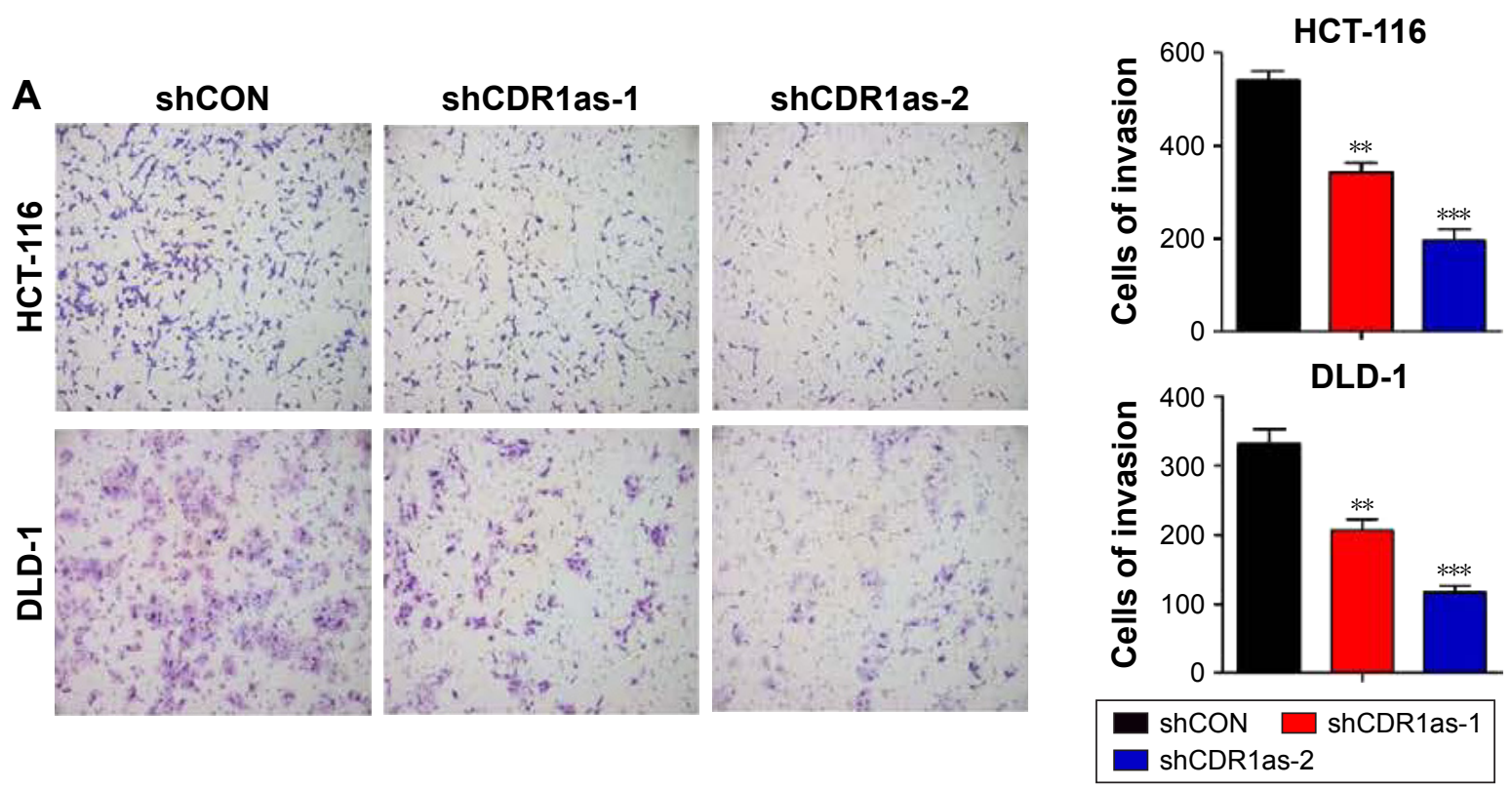

B

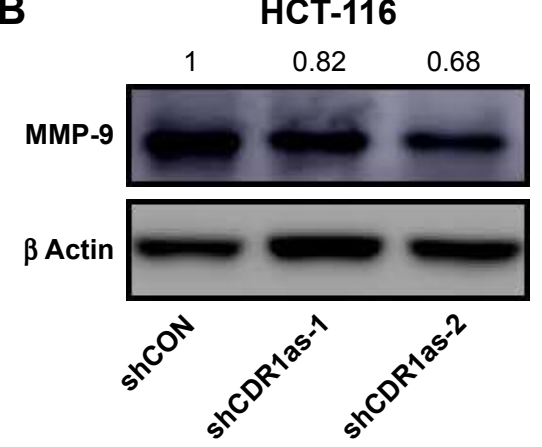

DLD-1

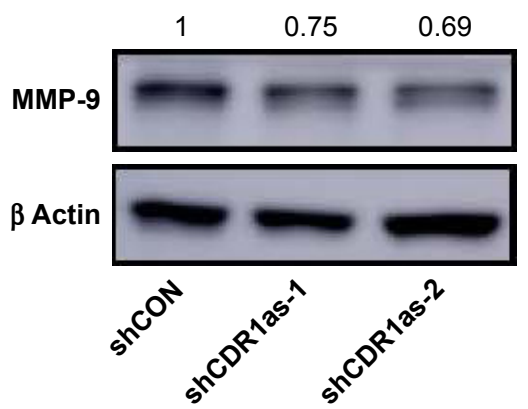

Figure 3 CDR las downregulation suppresses tumor cell invasion.

Notes: (A) Invasion images and counts of colon cancer cells infected with control or shCDR las lentivirus for $72 \mathrm{~h}$ (magnification I00X). (B) Western blot analysis of MMP-9 in HCT-II 6 and DLD-I cells infected with control or shCDRI as lentivirus for $72 \mathrm{~h}$. $* * P<0.0 \mathrm{l}$ and $* * * P<0.00 \mathrm{l}$.

Abbreviations: shCON, control-scrambled shRNA; shCDRIas, shRNA targeting CDRIas.

Moreover, the miR-7 inhibitor partially blocked the role of CDR1as knockdown. This indicated that CDR1as/miR-7 axis was associated with CRC progression.

Recent studies showed that CDR1as was a strong sponge for miR-7 in the embryonic zebrafish and islet cells. ${ }^{10,16}$ As for the function of CDR1as in cancer, it has been reported to be upregulated in HCC samples and knockdown of CDR1as inhibited HCC progression. ${ }^{17}$ CDRlas was further found to be one of the independent factors of hepatic macroscopic vascular invasion (MVI). CDR1as expression in
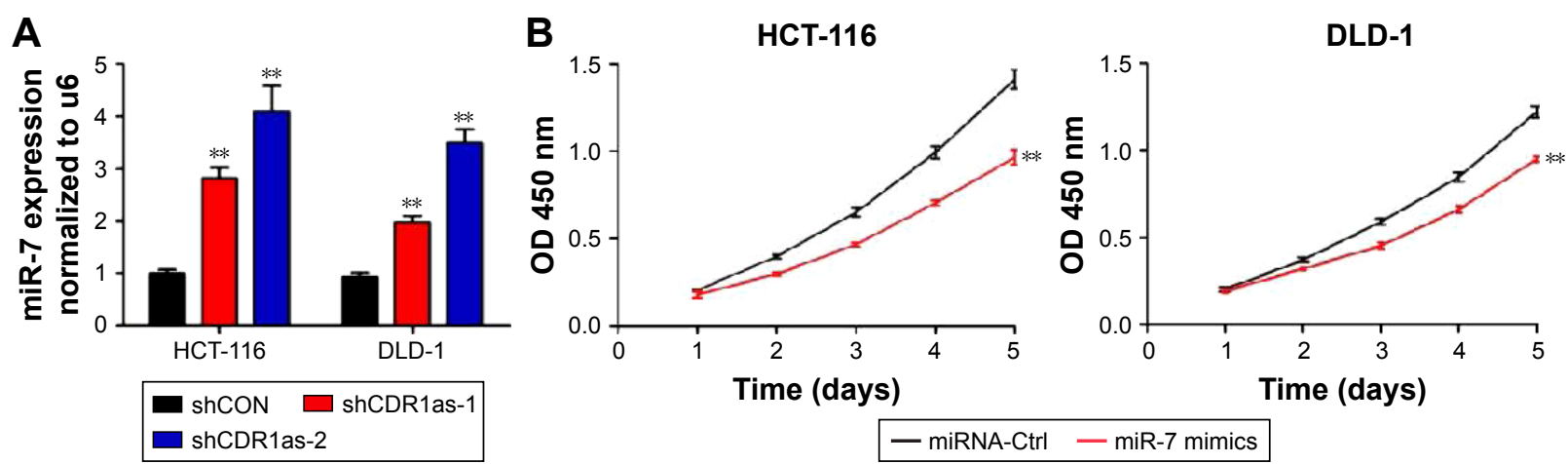

Figure 4 (Continued) 
C
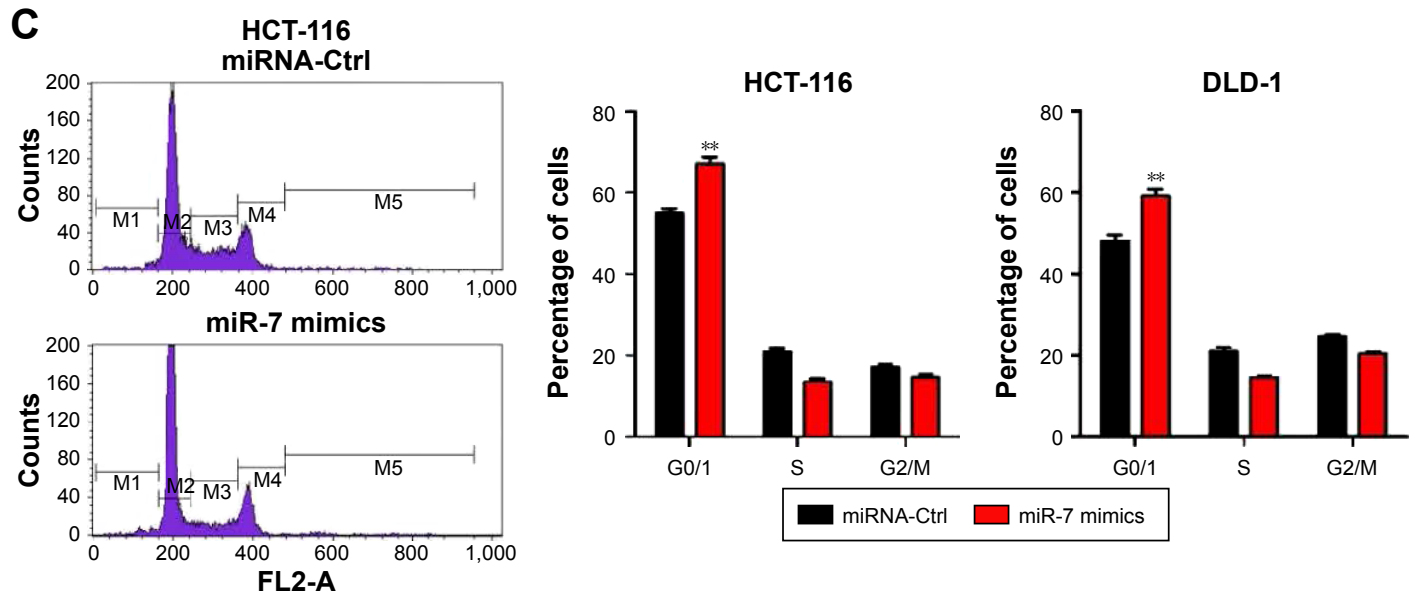

D

НСT-116
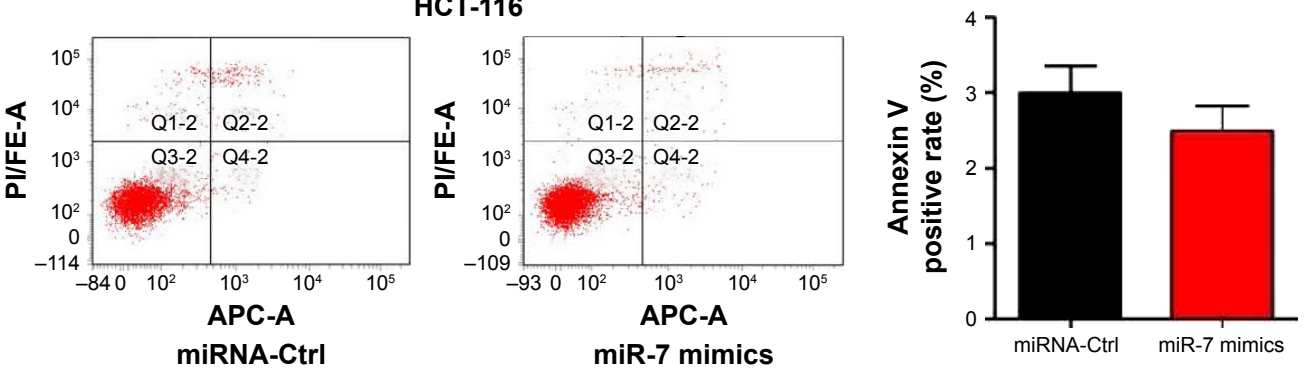

$\mathbf{E}$
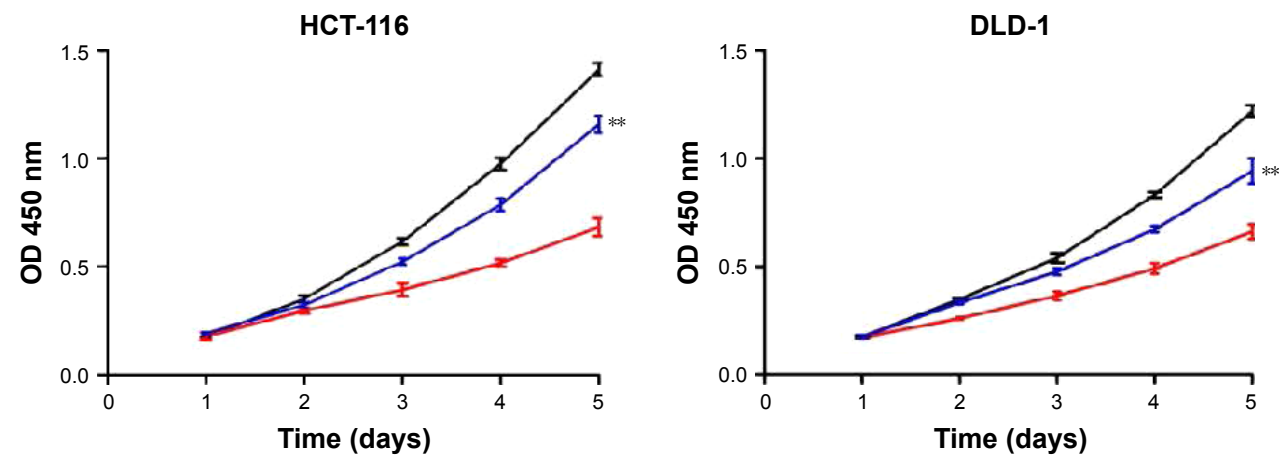

- shCON - shCDR1as-2 shCDR1as-2+ miR-7 inhibitor

$\mathbf{F}$

HCT-116
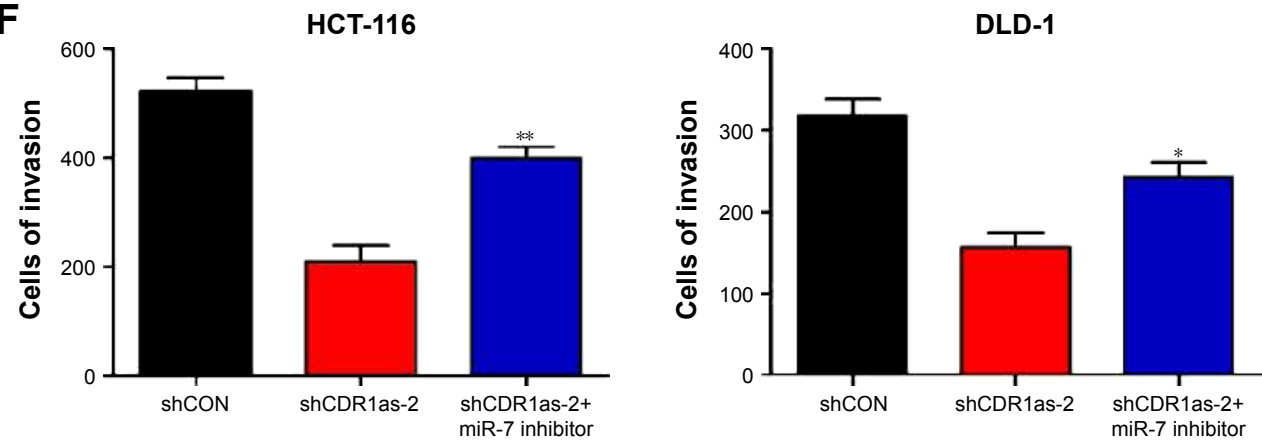

Figure $4 \mathrm{CDR}$ las promotes cell growth and invasion through partially blocking miR-7.

Notes: (A) qRT-PCR analysis of miR-7 expression in shCON and shCDR las lentivirus-infected HCT-I 16 and DLD-I cells for 72 h. (B) Growth curves of miRNA-Ctrl and miR-7 mimics in HCT-116 and DLD-I cells for 5 days. (C) Cell-cycle distributions of HCT-1 16 and DLD-I cells transfected with miRNA-Ctrl or miR-7 mimics for 48 h. (D) miR-7 mimics did not significantly increase apoptosis rate in colon cancer HCT-1/6 cells. (E) Growth curves of shCON, shCDR las, and shCDR Ias plus the miR-7 inhibitor in HCT-1 I6 and DLD-I cells. (F) Invasion images and counts of HCT-II6 and DLD-I cells treated by shCON, shCDR I as, and shCDR Ias plus the miR-7 inhibitor. $* P<0.05$ and $* * P<0.01$.

Abbreviations: miR-7, microRNA-7; qRT-PCR, quantitative reverse transcription polymerase chain reaction; shCON, control-scrambled shRNA; shCDRIas, shRNA targeting CDR Ias; miRNA, microRNA; Ctrl, control; OD, optical density. 

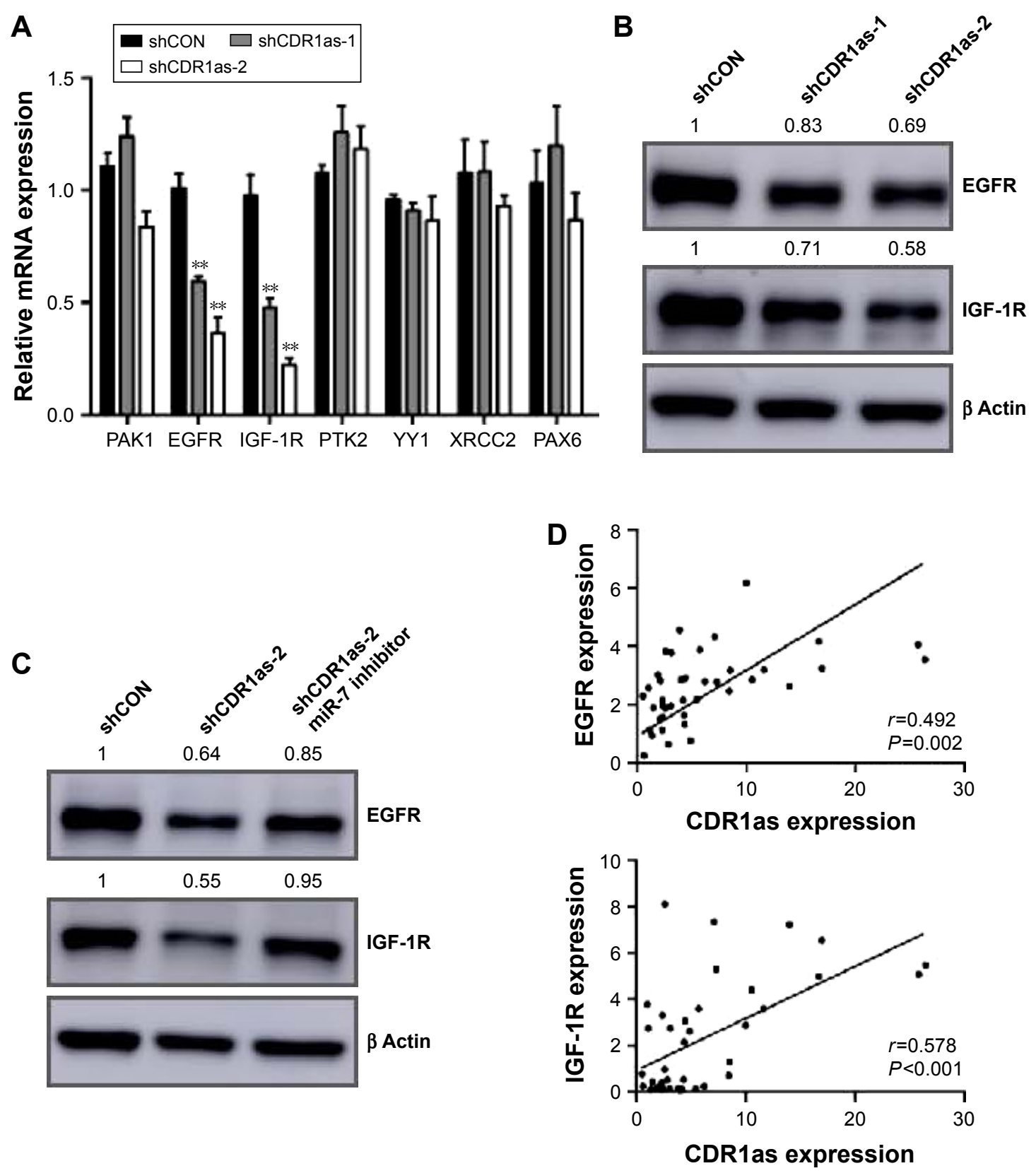

Figure 5 CDRI as positively regulates EGFR and IGF-IR in CRC.

Notes: (A) qRT-PCR analysis of miR-7-targeted genes in HCT-II6 cells infected with shCON and shCDR las lentivirus for $72 \mathrm{~h}$. (B) Western blot analysis of EGFR and IGF-IR following shCON and shCDR Ias lentivirus infection for $72 \mathrm{~h}$ in HCT-II6 cells. (C) Western blot analysis of EGFR and IGF-IR in HCT-II6 cells treated by shCON, shCDR Ias, and shCDRIas plus the miR-7 inhibitor for $72 \mathrm{~h}$. (D) EGFR and IGF-IR mRNA levels were positively correlated with CDRIas expression in CRC tumor samples. $* * p<0.01$.

Abbreviations: CRC, colorectal cancer; qRT-PCR, quantitative reverse transcription polymerase chain reaction; miR-7, microRNA-7; shCON, control-scrambled shRNA; shCDRIas, shRNA targeting CDRIas.

HCC tissues was positively correlated with hepatic MVI, alpha-fetoprotein levels, and younger age. ${ }^{18}$ However, the expression and role of CDR1as in CRC are still unknown. In this study, we found that CDR1as had a higher expression in CRC tumor samples than in adjacent normal mucosa, and a high CDR1as expression was correlated with poor OS. Our results further demonstrated that the function of CDR1as in $\mathrm{CRC}$ is partially dependent on miR-7. Although knockdown of CDR1as increased miR-7 expression in HCT-116 and DLD-1 cells, we did not see a significant adverse correlation between CDR1as and miR-7 in CRC tumor samples. This might be ascribed to the characteristic of CDR1as serving as an miR-7 sponge. CDR1as may bind and sequester miR-7, yet does not regulate miR-7 expression. When CDR1as is degraded, miR-7 may be released in cytoplasm, making it detectable..$^{17,19}$ In addition, miR-7 expression could also be 
regulated on both transcriptional and post-transcriptional levels. As for transcriptional regulation, HoxD10 can interact with the miR-7 chromatin and positively regulate miR-7 expression, resulting in a tumor suppressive phenotype. ${ }^{20}$ For post-transcriptional regulation, miR-7-1 biogenesis in non-brain cells was inhibited by HuR and MSI2 through forming a HuR/MSI2/pri-miR-7-1 complex, resulting in the stabilization of the pri-miR-7-1 structure. ${ }^{21}$ In addition, the miR-7 inhibitor partially blocking the function of CDR1as knockdown indicated that CDR1as may regulate CRC progression through other mechanisms. Some functions of circRNAs have been proposed, besides acting as miRNA sponges, including interactions with binding proteins and transcriptional and post-transcriptional regulations. ${ }^{13,22}$

To understand the biological role of CDR1as, the regulatory network of miR-7 needs to be considered. MiR-7 suppressed several oncogenic signaling pathways through directly targeting EGFR, IGF-1R, and PAK1, indicating a tumor-suppressive role for miR-7. ${ }^{20,23-25}$ Ectopic expression of miR-7 suppressed CRC cell proliferation and caused cell-cycle arrest in the G1 phase through targeting YY1. ${ }^{26}$ MiR-7 was further reported to have a low expression in CRC samples, and miR-7 upregulation inhibited CRC cell invasion by regulating its direct target PAX6. ${ }^{27} \mathrm{MiR}-7$ was also reported to regulate cetuximab sensitivity, and a low expression of miR-7 was an independent and significant prognostic factor for survival. ${ }^{28}$ Our study also revealed an inhibitory role of miR-7 in CRC, which is similar to CDRlas knockdown. Furthermore, we identified that EGFR and IGF-1R are direct targets of CDR1as/ miR-7 axis, indicating that EGFR and IGF-1R may participate in the oncogenic function of CDR1as/miR-7 axis.

Both EGFR and IGF-1R were extensively studied in tumors. EGFR was reported to mediate multiple cellular functions, including proliferation, apoptosis, migration, differentiation, and dedifferentiation. ${ }^{29}$ In addition, the antiEGFR antibody cetuximab had greatly increased the survival of patients with RAS wild-type metastatic CRC. ${ }^{30}$ IGF-1R is overexpressed in CRC tumor samples and promotes tumor growth, angiogenesis, and metastasis. ${ }^{31-33}$ In addition, activation of IGF-1R is linked to anti-EGFR therapy resistance and poor prognosis in CRC. ${ }^{34}$ Our study showed that CDR1as expression was positively associated with $E G F R$ and $I G F-1 R$ expression in CRC tumor samples, further suggesting that CDR1as/miR-7 axis may promote CRC progression through regulating EGFR and IGF-1R.

\section{Conclusion}

This study demonstrated that CDRlas overexpression is associated with poor survival of CRC patients and that knockdown of CDR1as suppresses CRC cell proliferation and invasion through upregulating miR-7. In addition, we found that EGFR and IGF-1R are direct targets of CDR1as/miR-7 axis and both $E G F R$ and $I G F-1 R$ expression are positively associated with CDR1as expression in CRC samples. Based on these observations, we suggest that aberrant CDR1as/ miR-7 axis may serve as a promising molecular target for designing novel therapies to control CRC progression.

\section{Acknowledgments}

This work was supported by the National Natural Science Foundation of China (81272390, 81372315, and 81402341). The work was also supported in part by the Shanghai Science and Technology Committee Project (13JC1401601). We thank Pingping Xu, Qi Lin, and Dexiang Zhu from the Zhongshan Hospital of Fudan University for collecting the clinical data. We also thank Elizabeth Ashley Ballard from the Wake Forest Baptist Medical Center for the revision of this manuscript.

\section{Disclosure}

The authors report no conflicts of interest in this work.

\section{References}

1. Siegel RL, Miller KD, Jemal A. Cancer statistics, 2016. CA Cancer J Clin. 2016;66(1):7-30.

2. Ferlay J, Soerjomataram I, Dikshit R, et al. Cancer incidence and mortality worldwide: sources, methods and major patterns in GLOBOCAN 2012. Int J Cancer. 2015;136(5):E359-E386.

3. Chen W, Zheng R, Baade PD, et al. Cancer statistics in China, 2015. CA Cancer J Clin. 2016;66(2):115-132.

4. Siegel R, Desantis C, Jemal A. Colorectal cancer statistics, 2014. CA Cancer J Clin. 2014;64(2):104-117.

5. Van Cutsem E, Cervantes A, Nordlinger B, Arnold D. Metastatic colorectal cancer: ESMO clinical practice guidelines for diagnosis, treatment and follow-up. Ann Oncol. 2014;25(suppl 3):iii1-iii9.

6. Hsu MT, Coca-Prados M. Electron microscopic evidence for the circular form of RNA in the cytoplasm of eukaryotic cells. Nature. 1979; 280(5720):339-340.

7. Cocquerelle C, Mascrez B, Hetuin D, Bailleul B. Mis-splicing yields circular RNA molecules. FASEB J. 1993;7(1):155-160.

8. Salzman J, Gawad C, Wang PL, Lacayo N, Brown PO. Circular RNAs are the predominant transcript isoform from hundreds of human genes in diverse cell types. PLoS One. 2012;7(2):e30733.

9. Hansen TB, Jensen TI, Clausen BH, et al. Natural RNA circles function as efficient microRNA sponges. Nature. 2013;495(7441):384-388.

10. Memczak S, Jens M, Elefsinioti A, et al. Circular RNAs are a large class of animal RNAs with regulatory potency. Nature. 2013;495(7441): 333-338.

11. Salzman J, Chen RE, Olsen MN, Wang PL, Brown PO. Cell-type specific features of circular RNA expression. PLoS Genet. 2013;9(9): e1003777.

12. Jeck WR, Sorrentino JA, Wang K, et al. Circular RNAs are abundant, conserved, and associated with ALU repeats. RNA. 2013;19(2): 141-157.

13. Jeck WR, Sharpless NE. Detecting and characterizing circular RNAs. Nat Biotechnol. 2014;32(5):453-461.

14. Wang PL, Bao Y, Yee MC, et al. Circular RNA is expressed across the eukaryotic tree of life. PLoS One. 2014;9(6):e90859. 
15. Li F, Zhang L, Li W, et al. Circular RNA ITCH has inhibitory effect on ESCC by suppressing the Wnt/beta-catenin pathway. Oncotarget. 2015;6(8):6001-6013.

16. Xu H, Guo S, Li W, Yu P. The circular RNA Cdrlas, via miR-7 and its targets, regulates insulin transcription and secretion in islet cells. $\mathrm{Sci}$ Rep. 2015;5:12453.

17. Yu L, Gong X, Sun L, Zhou Q, Lu B, Zhu L. The Circular RNA Cdr1as Act as an oncogene in hepatocellular carcinoma through targeting miR-7 expression. PLoS One. 2016;11(7):e0158347.

18. Xu L, Zhang M, Zheng X, Yi P, Lan C, Xu M. The circular RNA ciRS-7 (Cdrlas) acts as a risk factor of hepatic microvascular invasion in hepatocellular carcinoma. J Cancer Res Clin Oncol. 2017;143(1):17-27.

19. Hansen TB, Kjems J, Damgaard CK. Circular RNA and miR-7 in cancer. Cancer Res. 2013;73(18):5609-5612.

20. Reddy SD, Ohshiro K, Rayala SK, Kumar R. MicroRNA-7, a homeobox D10 target, inhibits p21-activated kinase 1 and regulates its functions. Cancer Res. 2008;68(20):8195-8200.

21. Choudhury NR, de Lima Alves F, de Andres-Aguayo L, et al. Tissuespecific control of brain-enriched miR-7 biogenesis. Genes Dev. 2013;27(1):24-38.

22. Peng L, Yuan XQ, Li GC. The emerging landscape of circular RNA ciRS-7 in cancer (Review). Oncol Rep. 2015;33(6):2669-2674.

23. Fang Y, Xue JL, Shen Q, Chen J, Tian L. MicroRNA-7 inhibits tumor growth and metastasis by targeting the phosphoinositide 3-kinase/ Akt pathway in hepatocellular carcinoma. Hepatology. 2012;55(6): 1852-1862.

24. Webster RJ, Giles KM, Price KJ, Zhang PM, Mattick JS, Leedman PJ. Regulation of epidermal growth factor receptor signaling in human cancer cells by microRNA-7. J Biol Chem. 2009;284(9):5731-5741.

25. Jiang L, Liu X, Chen Z, et al. MicroRNA-7 targets IGF1R (insulin-like growth factor 1 receptor) in tongue squamous cell carcinoma cells Biochem J. 2010;432(1):199-205.
26. Zhang $\mathrm{N}$, Li $\mathrm{X}, \mathrm{Wu} \mathrm{CW}$, et al. microRNA-7 is a novel inhibitor of YY1 contributing to colorectal tumorigenesis. Oncogene. 2013; 32(42):5078-5088.

27. Li Y, Li Y, Liu Y, Xie P, Li F, Li G. PAX6, a novel target of microRNA-7, promotes cellular proliferation and invasion in human colorectal cancer cells. Dig Dis Sci. 2014;59(3):598-606.

28. Suto T, Yokobori T, Yajima R, et al. MicroRNA-7 expression in colorectal cancer is associated with poor prognosis and regulates cetuximab sensitivity via EGFR regulation. Carcinogenesis. 2015;36(3): $338-345$.

29. Cohen RB. Epidermal growth factor receptor as a therapeutic target in colorectal cancer. Clin Colorectal Cancer. 2003;2(4):246-251.

30. Van Cutsem E, Kohne CH, Hitre E, et al. Cetuximab and chemotherapy as initial treatment for metastatic colorectal cancer. $N$ Engl J Med. 2009;360(14):1408-1417.

31. Reinmuth N, Liu W, Fan F, et al. Blockade of insulin-like growth factor I receptor function inhibits growth and angiogenesis of colon cancer. Clin Cancer Res. 2002;8(10):3259-3269.

32. Reinmuth N, Fan F, Liu W, et al. Impact of insulin-like growth factor receptor-I function on angiogenesis, growth, and metastasis of colon cancer. Lab Invest. 2002;82(10):1377-1389.

33. Sekharam $M$, Zhao $H$, Sun $M$, et al. Insulin-like growth factor 1 receptor enhances invasion and induces resistance to apoptosis of colon cancer cells through the Akt/Bcl-x(L) pathway. Cancer Res. 2003;63(22):7708-7716.

34. Coppola D, Ferber A, Miura M, et al. A functional insulin-like growth factor I receptor is required for the mitogenic and transforming activities of the epidermal growth factor receptor. Mol Cell Biol. 1994;14(7):4588-4595. 


\section{Supplementary materials}

Table SI Specific real-time qPCR primers

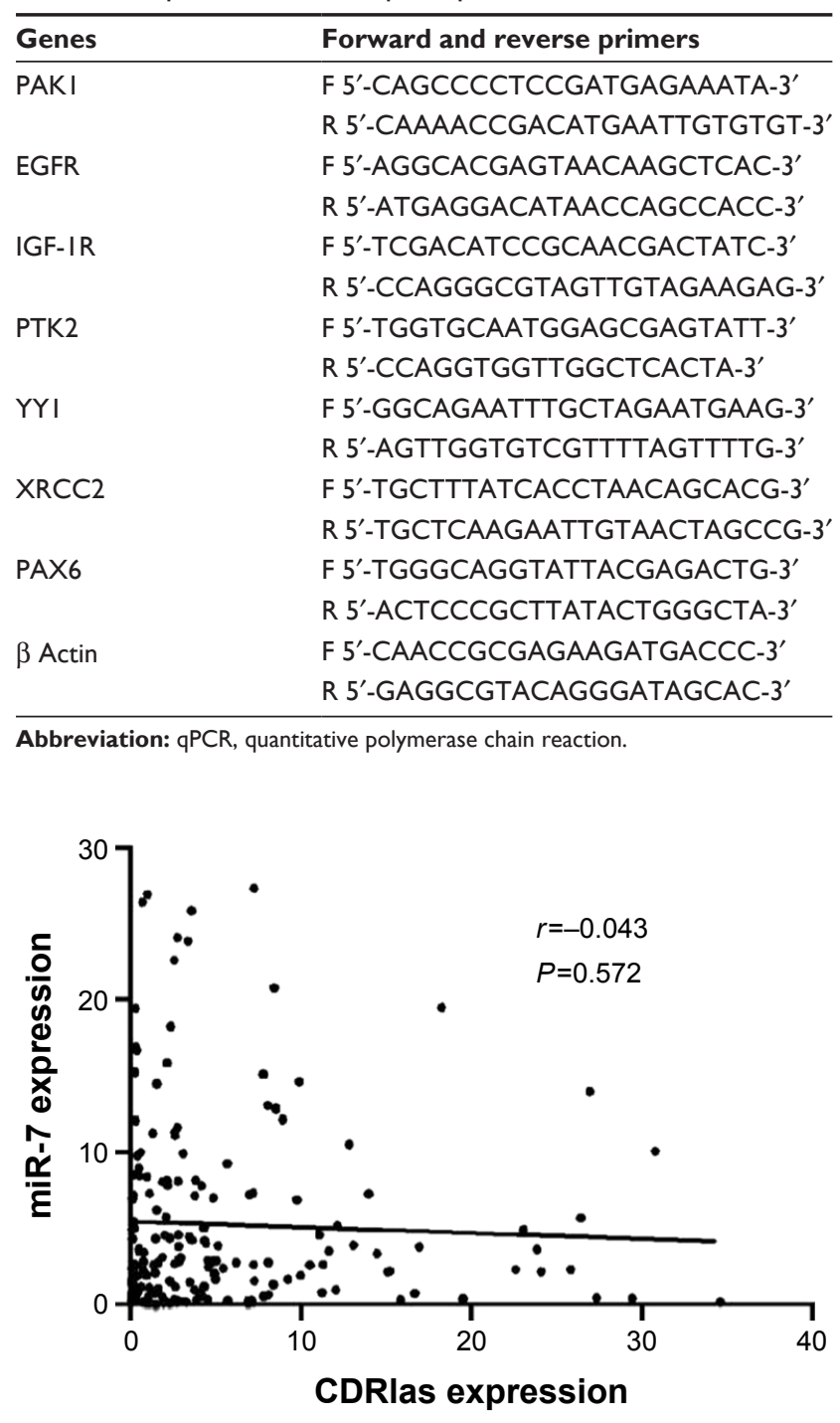

Figure SI CDRlas expression is not correlated with miR-7.

Note: Pearson correlation analysis of CDRlas and miR-7 expression in I82 CRC tumor samples.

Abbreviations: miR-7, microRNA-7; CRC, colorectal cancer.

OncoTargets and Therapy

\section{Publish your work in this journal}

OncoTargets and Therapy is an international, peer-reviewed, open access journal focusing on the pathological basis of all cancers, potential targets for therapy and treatment protocols employed to improve the management of cancer patients. The journal also focuses on the impact of management programs and new therapeutic agents and protocols on
Table S2 Correlations between miR-7 expression and clinicopathological parameters in CRC

\begin{tabular}{|c|c|c|c|}
\hline Characteristic & $\mathbf{n}$ & $\begin{array}{l}\text { miR-7 expression, } \\
\text { median (range) }\end{array}$ & $P$-value \\
\hline Sex & & & 0.357 \\
\hline Female & 83 & $2.78(0.76-6.72)$ & \\
\hline Male & 99 & $3.34(1.18-7.12)$ & \\
\hline Age (years) & & & 0.335 \\
\hline$<60$ & 68 & $2.54(0.48-6.13)$ & \\
\hline$\geq 60$ & 114 & $2.92(1.04-7.02)$ & \\
\hline Location & & & 0.713 \\
\hline Right colon & 40 & $2.7 \mathrm{I}(0.84-5.63)$ & \\
\hline Left colon & 57 & $2.85(0.78-8.4 I)$ & \\
\hline Rectum & 85 & $2.80(1.00-5.78)$ & \\
\hline Tumor size $(\mathrm{cm})$ & & & 0.092 \\
\hline$<5$ & 111 & $3.54(1.22-7.98)$ & \\
\hline$\geq 5$ & 71 & $2.73(0.63-6.82)$ & \\
\hline Histology & & & 0.553 \\
\hline Adenocarcinoma & 149 & $2.64(1.01-7.38)$ & \\
\hline Mucinous adenocarcinoma & 33 & $2.43(0.75-6.43)$ & \\
\hline Primary $\mathrm{pT}$ stage & & & 0.148 \\
\hline $1 / 2$ & 37 & $2.65(0.97-5.68)$ & \\
\hline $3 / 4$ & 145 & $2.14(1.05-7.76)$ & \\
\hline Primary pN stage & & & 0.658 \\
\hline 0 & 95 & $2.08(1.30-7.39)$ & \\
\hline $1 / 2$ & 87 & $2.15(0.58-7.45)$ & \\
\hline Synchronous distant metastasis & & & 0.493 \\
\hline No & 158 & $3.10(2.13-7.19)$ & \\
\hline Yes & 24 & $2.95(0.82-6.29)$ & \\
\hline Stage & & & 0.348 \\
\hline I, II & 88 & $2.96(1.26-7.38)$ & \\
\hline III, IV & 94 & $2.32(0.64-6.90)$ & \\
\hline Preoperative CEA level & & & 0.632 \\
\hline$<5$ & 99 & $2.88(0.67-7.3 \mathrm{I})$ & \\
\hline $5-19$ & 49 & $2.35(0.80-5.03)$ & \\
\hline$\geq 20$ & 34 & $3.27(1.43-7.97)$ & \\
\hline
\end{tabular}

Abbreviations: CRC, colorectal cancer; CEA, carcinoembryonic antigen.

\section{Dovepress}

patient perspectives such as quality of life, adherence and satisfaction. The manuscript management system is completely online and includes a very quick and fair peer-review system, which is all easy to use. Visit http://www.dovepress.com/testimonials.php to read real quotes from published authors. 